\title{
Kinetic Modeling for Chemiluminescent Radicals in Acetylene Combustion
}

\author{
Carla S. T. Marques, ${ }^{*, \# ~ L e a n d r o ~ H . ~ B e n v e n u t t i ~ a n d ~ C e l s o ~ A . ~ B e r t r a n ~}$ \\ Instituto de Química, Universidade Estadual de Campinas, CP 6154, 13083-970 Campinas-SP, Brazil
}

\begin{abstract}
Uma modelagem cinética foi avaliada para reproduzir a quimiluminescência experimental dos radicais excitados $\mathrm{OH}^{*}, \mathrm{CHO}^{*}, \mathrm{CH}^{*}$ e $\mathrm{C}_{2} *$ formados na combustão de $\mathrm{C}_{2} \mathrm{H}_{2} / \mathrm{O}_{2}$ em uma câmara fechada. Um mecanismo reacional com 37 espécies e 106 reações elementares foi validado para a combustão de $\mathrm{C}_{2} \mathrm{H}_{2} / \mathrm{O}_{2} \operatorname{com} \Phi=1.00$ e $\Phi=1.62$, através das medidas de quimiluminescência. Para isso foram incluídas reações de formação e de decaimento dos radicais excitados. As simulações foram realizadas com o pacote KINAL; o programa DIFF foi utilizado para resolver as equações diferenciais ordinárias e o programa ROPA para realizar a análise das velocidades de produção. Houve uma boa concordância entre os perfis de quimiluminescência experimental e simulado de todos os radicais e para ambas reações. Os resultados mostraram que o $\mathrm{CH}$ tem um papel central na formação dos radicais. As reações: $\mathrm{H}+\mathrm{O}_{2}=\mathrm{OH}^{*}+\mathrm{O}$; $\mathrm{CH}$ $+\mathrm{O}=\mathrm{CHO}^{*} ; \mathrm{C}_{2} \mathrm{H}+\mathrm{O}_{2}=\mathrm{CH}^{*}+\mathrm{CO}_{2}$ e $\mathrm{CH}_{2}+\mathrm{C}=\mathrm{C}_{2}{ }^{*}+\mathrm{H}_{2}$ são as principais rotas reacionais para reproduzir os perfis experimentais.
\end{abstract}

Kinetic modeling to reproduce the experimental chemiluminescence of $\mathrm{OH}^{*}, \mathrm{CHO}^{*}, \mathrm{CH}^{*}$ and $\mathrm{C}_{2} *$ excited radicals formed in $\mathrm{C}_{2} \mathrm{H}_{2} / \mathrm{O}_{2}$ combustion in a closed chamber was evaluated. A reaction mechanism with 37 species and 106 elementary reactions for $\mathrm{C}_{2} \mathrm{H}_{2} / \mathrm{O}_{2}$ combustion at $\Phi=1.00$ and $\Phi=1.62$ was validated through chemiluminescence measurements, where formation and decay reactions of excited radicals are included. KINAL package was used for simulations. Ordinary differential equations were solved by the DIFF program and production rate analysis were acquired by the ROPA program. There was good agreement between experimental and simulated chemiluminescence profiles of all radicals for both combustions. The results showed $\mathrm{CH}$ has a meaningful role in the production of excited radicals. Reactions: $\mathrm{H}+\mathrm{O}_{2}=\mathrm{OH}^{*}+\mathrm{O}$; $\mathrm{CH}+\mathrm{O}=\mathrm{CHO}^{*} ; \mathrm{C}_{2} \mathrm{H}+\mathrm{O}_{2}=\mathrm{CH}^{*}+\mathrm{CO}_{2}$ and $\mathrm{CH}_{2}+\mathrm{C}=\mathrm{C}_{2} *+\mathrm{H}_{2}$ were the main reactions paths used to reproduce the experimental profiles.

Keywords: reaction mechanism, chemiluminescence, acetylene, combustion, closed chamber

\section{Introduction}

Acetylene is one of the major intermediates in any hydrocarbon flame and its oxidation is relevant to important phenomena and chemical processes occurring in the combustion of hydrocarbon fuels..$^{1-3}$ Acetylene plays a role in processes like polycyclic aromatic hydrocarbons (PAH), soot and prompt-NO formation, and chemiionization and chemiluminescence in combustion chemistry, due to its oxidation products, which are highly reactive small radicals, such as $\mathrm{CHCO}$, $\mathrm{CH}_{2}, \mathrm{CH}$ and $\mathrm{C}_{2} \mathrm{H} \cdot{ }^{1-3}$ Consequently, the oxidation chemistry of acetylene has a significant influence on

*e-mail: carlatm@ieav.cta.br

\#Present Address: Instituto de Estudos Avançados, Centro Técnico Aeroespacial, Rodovia dos Tamoios, km 5,5, 12228-840, São José dos Campos, SP - Brazil mechanisms involved in heavier hydrocarbon flames and, thus, the kinetic modeling of acetylene combustion is of great significance.

However, most computational studies on combustion mechanisms, where acetylene itself is the principal fuel, have focused on laminar flames and benzene formation was the main concern..$^{4-8}$ Very little attention has been directed to the chemistry of small hydrocarbon radicals produced in acetylene flames. ${ }^{9-11}$

Kinetic modeling results usually describe concentration profiles of stable species and free radicals in the ground electronic states that can be validated by experimental data, which have been generally obtained using molecular-beam mass spectrometry and laser induced fluorescence. . $^{5,6,10,12,13}$

Although the chemiluminescent radicals are minor species, they are probes of the combustion processes since 
they are intermediate species with short lifetimes that characterize the reaction zones, where the reagents are principally consumed. Thus, they are suitable to use in following the chemistry of small species and other features of the combustion reactions.

In this work, a mechanism is proposed and validated for acetylene combustion in a small closed chamber, where fixed $\mathrm{C}_{2} \mathrm{H}_{2} / \mathrm{O}_{2}$ premixed amounts at a given initial pressure were ignited, using chemiluminescence data. To validate the proposed mechanism the reactions for excited radical formation and decay are considered and the simulated and experimental chemiluminescence profiles resulting from decay of excited radicals were compared. Based on the analysis of production rates of the kinetic modeling established, the key reaction paths for the production of the excited radicals are also identified.

\section{Experimental}

\section{Experimental setup}

The combustion system used to obtain the experimental chemiluminescence profiles of $\mathrm{OH}^{*}, \mathrm{CHO}^{*}, \mathrm{CH}^{*}$ and $\mathrm{C}_{2} *$ excited radicals is the same as that previously reported $^{14}$ and thus, will be described briefly.

The combustion reactions were carried out in a closed chamber with constant small volume (ca. $200 \mathrm{ml}$ ). The gaseous mixtures were prepared using a vacuum manifold to introduce acetylene and oxygen directly into the combustion chamber at a fixed initial composition and pressure. The combustible mixture was ignited by a spark plug at the center of the combustion chamber.

The light emitted from the reaction inside the whole chamber was analyzed by a monochromator (Oriel, 77200), detected simultaneously by a photodiode and a photomultiplier (Burle, 1P28A) and recorded by an oscilloscope (Nicolet, 450). Once the combustion of the fixed mixture amount is initiated, the large number of species produced reacts among themselves and with the original components of the initial mixture, until the reaction rate falls off, while exhibiting a defined chemiluminescence time behavior.

The total chemiluminescences produced in the stoichiometric $(\Phi=1.00)$ and fuel-rich $(\Phi=1.62) \mathrm{C}_{2} \mathrm{H}_{2} / \mathrm{O}_{2}$ flames at 140 torr were measured setting the diffraction grating of the monochromator to reflect the light emitted from these processes $\left(\Phi=\frac{P_{C 2 \mathrm{H} 2} / P_{O 2}}{S . R .}\right.$, where S.R. is the stoichiometric ratio for $\mathrm{C}_{2} \mathrm{H}_{2}+\mathrm{O}_{2}=\mathrm{CO}_{2}+\mathrm{H}_{2} \mathrm{O}$ reaction).

Chemiluminescence profiles as a function of time from our previous work ${ }^{14}$ for each emitter at the heads of the emission bands for $\mathrm{OH}^{*}\left(\mathrm{~A}^{2} \Sigma \rightarrow \mathrm{X}^{2} \Pi\right), \mathrm{CHO}^{*}\left(\mathrm{~A}^{2} \Pi \rightarrow\right.$ $\left.\mathrm{X}^{2} \mathrm{~A}^{\prime}\right), \mathrm{CH}^{*}\left(\mathrm{~A}^{2} \Delta \rightarrow \mathrm{X}^{2} \Pi\right)$ and $\mathrm{C}_{2} *\left(\mathrm{~A}^{3} \Pi \rightarrow \mathrm{X}^{3} \Pi\right)$ excited radical transitions, for both stoichiometric and fuel-rich flames, are also presented.

\section{Calculation methods}

Numerical methods for kinetic modeling have been fully discussed in the literature and thus will only be described briefly. ${ }^{15-18}$ The kinetic model can be expressed by a set of coupled ordinary differential equations. The equation system is described as: $d Y i / d t=f(Y i(t), \ldots, Y j(t), t, k)$, where $Y i$ represents the chemical species $i$ and $k$ represents the vector of the kinetic parameters. In this work, we have used the KINAL program package, ${ }^{19}$ which is a public domain program based on the Runge-Kutta-4-semiimplicit method. ${ }^{20}$ The system of coupled ordinary differential equations are automatically generated and solved by the DIFF program of the KINAL package.

The classic method for the study of the reaction relevance is the production rate analysis ${ }^{21,22}$ and this was carried out by the ROPA program of the KINAL package. The production rate analysis requires calculation of the Pij matrix elements, which show the contribution of reaction $j$ to the rate of production of species $i .^{23,24}$

\section{Reaction mechanism}

The proposed reaction mechanism for $\mathrm{C}_{2} \mathrm{H}_{2} / \mathrm{O}_{2}$ homogeneous combustion developed in this study consists of 37 species and 106 elementary reactions, as listed in Table 1. These were proposed in order to reproduce the experimental chemiluminescences of $\mathrm{OH}^{*}, \mathrm{CHO}^{*}, \mathrm{CH}^{*}$ and $\mathrm{C}_{2} *$ excited radicals obtained in an earlier study for stoichiometric and fuel-rich $\mathrm{C}_{2} \mathrm{H}_{2} / \mathrm{O}_{2}$ combustion in a closed chamber at 140 torr. $^{14}$

The starting mechanism was based on the studies of Eraslan and Brown ${ }^{9}$ and Hidaka et al. ${ }^{10}$ with the addition of a set of reactions involving electronically excited species (formation reactions, radiative decay and collisional deactivation reactions and reactions between excited radicals and other species). The initial mechanism also included reverse reactions. They were each inserted, as new reactions, since the KINAL package only works with forward reactions.

Reactions of electronically excited species and their kinetic parameters are limited in the literature, except for the $\mathrm{CH}^{*}$ radical. All of proposed reactions for the production of $\mathrm{CH}^{*}$ radical and also the other reactions in which $\mathrm{CH}^{*}$ participates (as collisional and radiative deactivations, and reactions between $\mathrm{CH}^{*}$ and other species in the ground state) have been studied and modeled 
Table 1. Optimized reaction mechanism for $\mathrm{C}_{2} \mathrm{H}_{2} / \mathrm{O}_{2}$ combustions. Reaction rate coefficients are presented in the form $\mathrm{k}=\mathrm{A} \mathrm{T}^{\mathrm{n}}$ exp(-Ea/RT) and units are in $\mathrm{cm}^{3}$, mol, $\mathrm{s}, \mathrm{K}$ and $\mathrm{kcal} \mathrm{mol}^{-1}$, respectively

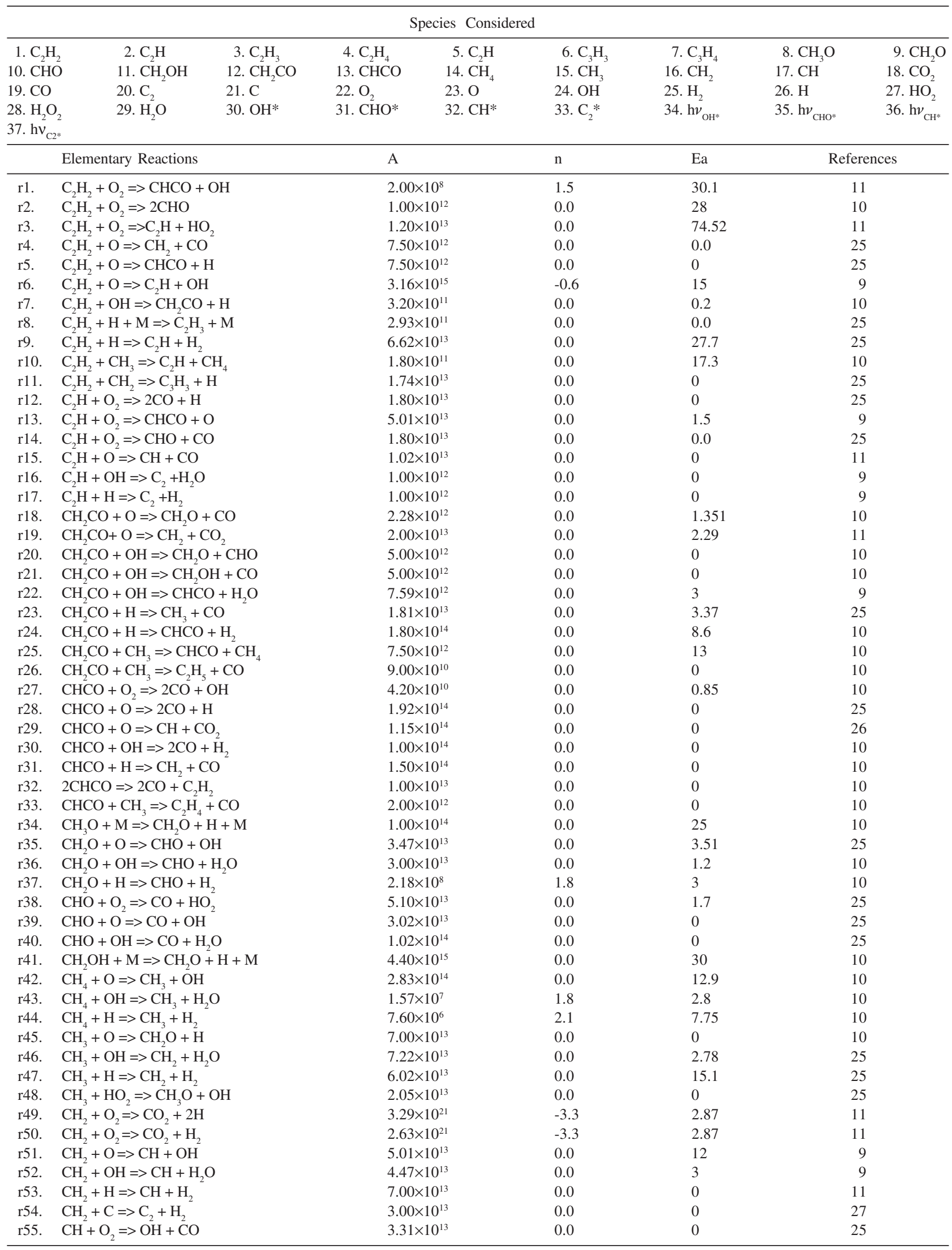


Table 1. (cont.)

\begin{tabular}{|c|c|c|c|c|c|}
\hline & Elementary Reactions & A & $\mathrm{n}$ & $\mathrm{Ea}$ & References \\
\hline r56. & $\mathrm{CH}+\mathrm{OH}=>\mathrm{C}+\mathrm{H}_{2} \mathrm{O}$ & $4.00 \times 10^{7}$ & 2.0 & 3 & 11 \\
\hline r57. & $\mathrm{CH}+\mathrm{H}=>\mathrm{C}+\mathrm{H}_{2}$ & $1.51 \times 10^{14}$ & 0.0 & 0 & 9 \\
\hline r58. & $\mathrm{CH}+\mathrm{C} \Rightarrow \mathrm{C}_{2}+\mathrm{H}$ & $1.00 \times 10^{14}$ & 0.0 & 0 & 27 \\
\hline r59. & $2 \mathrm{CH}=>\mathrm{C}_{2}+\mathrm{H}_{2}$ & $3.00 \times 10^{13}$ & 0.0 & 0 & 27 \\
\hline r60. & $\mathrm{CH}+\mathrm{O}_{2} \Rightarrow \mathrm{OH}^{*}+\mathrm{CO}$ & $3.85 \times 10^{13}$ & 0.0 & 0 & 28 \\
\hline r61. & $\mathrm{H}+\mathrm{O}_{2}=>\mathrm{OH}^{*}+\mathrm{O}$ & $9.75 \times 10^{13}$ & 0.0 & 14.851 & $25^{\mathrm{a}}$ \\
\hline r62. & $\mathrm{H}+\mathrm{O}^{2}=>\mathrm{OH}^{*}$ & $6.20 \times 10^{16}$ & -0.6 & 0 & $11^{\mathrm{a}}$ \\
\hline r63. & $\mathrm{OH}^{*}+\mathrm{M}=>\mathrm{OH}+\mathrm{M}$ & $9.26 \times 10^{13}$ & 0.0 & 0 & $29^{\mathrm{b}}$ \\
\hline r64. & $\mathrm{OH}^{*}=>\mathrm{OH}+\mathrm{h} v_{\mathrm{OH}^{*}}$ & $1.70 \times 10^{6}$ & 0.0 & 0 & 30 \\
\hline r65. & $\mathrm{CH}+\mathrm{O} \Rightarrow \mathrm{CHO}^{*}$ & $1.26 \times 10^{14}$ & 0.0 & 0 & $25^{\mathrm{a}}$ \\
\hline r66. & $\mathrm{CHO}^{*}+\mathrm{M}=>\mathrm{CHO}+\mathrm{M}$ & $8.67 \times 10^{13}$ & 0.0 & 0 & $31^{\mathrm{b}}$ \\
\hline r67. & $\mathrm{CHO}^{*}=>\mathrm{CHO}+\mathrm{h} v_{\mathrm{CHO}^{*}}$ & $3.30 \times 10^{10}$ & 0.0 & 0 & $32^{c}$ \\
\hline r68. & $\mathrm{C}_{2} \mathrm{H}+\mathrm{O}_{2}=>\mathrm{CH}^{*}+\mathrm{CO}_{2}$ & $4.47 \times 10^{15}$ & 0.0 & 25 & 9 \\
\hline r69. & $\mathrm{C}_{2}^{2} \mathrm{H}+\mathrm{O}^{2}=\mathrm{CH}^{*}+\mathrm{CO}^{2}$ & $1.44 \times 10^{13}$ & 0.0 & 0.45 & 33 \\
\hline r70. & $\mathrm{C}_{2}^{2}+\mathrm{OH}=>\mathrm{CH}^{*}+\mathrm{CO}$ & $3.39 \times 10^{12}$ & 0.0 & 0 & 9 \\
\hline r71. & $\mathrm{CH}^{*}+\mathrm{M}=>\mathrm{CH}+\mathrm{M}$ & $2.35 \times 10^{13}$ & 0.0 & 0 & $29^{\mathrm{b}}$ \\
\hline $\mathrm{r} 72$. & $\mathrm{CH}^{*}=>\mathrm{CH}+\mathrm{h} v_{\mathrm{CH}^{*}}$ & $1.61 \times 10^{6}$ & 0.0 & 0 & $34^{\mathrm{c}}$ \\
\hline r73. & $\mathrm{CH}_{2}+\mathrm{C} \Rightarrow \mathrm{C}_{2} *+\mathrm{H}_{2}$ & $3.00 \times 10^{13}$ & 0.0 & 0 & $27^{\mathrm{a}}$ \\
\hline r74. & $\mathrm{CH}^{2}+\mathrm{C} \Rightarrow \mathrm{C}_{2}^{2} *+\mathrm{H}^{2}$ & $1.00 \times 10^{14}$ & 0.0 & 0 & $27^{\mathrm{a}}$ \\
\hline r75. & $2 \mathrm{CH}=>\mathrm{C}_{2} *+\mathrm{H}_{2}$ & $3.00 \times 10^{13}$ & 0.0 & 0 & $27^{\mathrm{a}}$ \\
\hline r76. & $\mathrm{C}_{2} \mathrm{H}+\mathrm{H} \Rightarrow \mathrm{C}_{2} * \mathrm{H}_{2}$ & $1.00 \times 10^{12}$ & 0.0 & 0 & $9^{\mathrm{a}}$ \\
\hline r77. & $\mathrm{C}_{2}^{2} *+\mathrm{M}=>\mathrm{C}_{2}^{2}+\mathrm{M}^{2}$ & $2.05 \times 10^{12}$ & 0.0 & 0 & $35^{\mathrm{b}}$ \\
\hline r78. & $\mathrm{C}_{2}^{*}=>\mathrm{C}_{2}+\mathrm{h} v_{\mathrm{C}^{*}}$ & $5.26 \times 10^{6}$ & 0.0 & 0 & $36^{\mathrm{c}}$ \\
\hline r79. & $\mathrm{C}_{2}^{2}+\mathrm{H}_{2} \Rightarrow \mathrm{C}_{2} \mathrm{H}+\mathrm{H}$ & $6.00 \times 10^{13}$ & 0.0 & 2.92 & 27 \\
\hline r80. & $\mathrm{C}_{2}^{2} \mathrm{H}_{3}+\mathrm{O}_{2}=>\mathrm{C}_{2} \mathrm{H}_{2}+\mathrm{HO}_{2}$ & $1.00 \times 10^{12}$ & 0.0 & 0 & 10 \\
\hline r81. & $\mathrm{C}_{2}^{2} \mathrm{H}_{3}^{3}+\mathrm{O}_{2}^{2}=>\mathrm{CH}_{2}^{2} \mathrm{O}+\mathrm{CO}+\mathrm{H}$ & $5.40 \times 10^{10}$ & 0.0 & 0 & 10 \\
\hline r82. & $\mathrm{C}_{2}^{2} \mathrm{H}_{3}+\mathrm{O}^{2}=>\mathrm{CH}_{2}^{2} \mathrm{CO}+\mathrm{H}$ & $9.60 \times 10^{13}$ & 0.0 & 0 & 10 \\
\hline r83. & $\mathrm{C}_{2} \mathrm{H}_{4}+\mathrm{O} \Rightarrow \mathrm{CH}_{3}+\mathrm{CHO}$ & $1.33 \times 10^{8}$ & 1.55 & 0.428 & 10 \\
\hline r84. & $\mathrm{C}_{2}^{2} \mathrm{H}_{4}^{4}+\mathrm{OH} \Rightarrow \mathrm{C}_{2}^{3} \mathrm{H}_{3}+\mathrm{H}_{2} \mathrm{O}$ & $2.04 \times 10^{13}$ & 0.0 & 5.941 & 10 \\
\hline r85. & $\mathrm{C}_{2}^{2} \mathrm{H}_{5}^{4}=>\mathrm{C}_{2} \mathrm{H}_{4}+\mathrm{H}$ & $1.20 \times 10^{12}$ & 0.0 & 35 & 10 \\
\hline r86. & $\mathrm{C}_{3}^{2} \mathrm{H}_{3}+\mathrm{OH}=>\mathrm{CH}_{2} \mathrm{O}+\mathrm{C}_{2} \mathrm{H}_{2}$ & $5.01 \times 10^{11}$ & 0.0 & 0 & 9 \\
\hline r87. & $\mathrm{C}_{3} \mathrm{H}_{3}^{3}+\mathrm{H}=>\mathrm{C}_{3} \mathrm{H}_{4}^{2}$ & $2.00 \times 10^{13}$ & 0.0 & 0 & 9 \\
\hline r88. & $\mathrm{C}_{3}^{3} \mathrm{H}_{4}^{3}+\mathrm{OH}=>\mathrm{CH}_{2}^{4} \mathrm{CO}+\mathrm{CH}_{3}$ & $4.50 \times 10^{11}$ & 0.0 & 0 & 10 \\
\hline r89. & $\mathrm{C}_{3} \mathrm{H}_{4}^{4}+\mathrm{H}=>\mathrm{C}_{2} \mathrm{H}_{2}+\mathrm{CH}_{3}$ & $1.30 \times 10^{5}$ & 2.5 & 1 & 10 \\
\hline r90. & $\mathrm{C}_{3} \mathrm{H}_{4}^{4}+\mathrm{CH}_{3}=>\mathrm{C}_{3}^{2} \mathrm{H}_{3}+\mathrm{CH}_{4}$ & $2.00 \times 10^{12}$ & 0.0 & 7.7 & 10 \\
\hline r91. & $\mathrm{H}+\mathrm{O}_{2}=>\mathrm{OH}+\mathrm{O}$ & $9.75 \times 10^{13}$ & 0.0 & 14.851 & 25 \\
\hline r92. & $\mathrm{H}_{2}+\mathrm{O} \Rightarrow \mathrm{OH}+\mathrm{H}$ & $1.78 \times 10^{12}$ & 0.0 & 0 & 25 \\
\hline r93. & $\mathrm{H}_{2}+\mathrm{OH}=>\mathrm{H}_{2} \mathrm{O}+\mathrm{H}$ & $1.02 \times 10^{8}$ & 1.6 & 3.287 & 25 \\
\hline r94. & $\mathrm{H}+\mathrm{HO}_{2}=>2 \mathrm{OH}$ & $1.50 \times 10^{14}$ & 0.0 & 1 & 10 \\
\hline r95. & $\mathrm{H}+\mathrm{HO}_{2}^{2}=>\mathrm{H}_{2}+\mathrm{O}_{2}$ & $1.00 \times 10^{14}$ & 0.0 & 0.7 & 10 \\
\hline r96. & $\mathrm{OH}+\mathrm{O}^{2}=>\mathrm{H}+\mathrm{O}_{2}$ & $1.00 \times 10^{13}$ & 0.0 & 0 & 25 \\
\hline r97. & $\mathrm{OH}+\mathrm{HO}_{2}=>\mathrm{H}_{2} \mathrm{O}+\mathrm{O}_{2}$ & $2.89 \times 10^{13}$ & 0.0 & -0.495 & 25 \\
\hline r98. & $\mathrm{HO}_{2}+\mathrm{O}^{2}=\mathrm{OH}+\mathrm{O}_{2}^{2}$ & $1.00 \times 10^{14}$ & 0.0 & 0 & 25 \\
\hline r99. & $2 \mathrm{HO}_{2}^{2}=>\mathrm{H}_{2} \mathrm{O}_{2}+\mathrm{O}_{2}^{2}$ & $2.00 \times 10^{12}$ & 0.0 & 0 & 9 \\
\hline r100. & $\mathrm{H}_{2} \mathrm{O}_{2}+\mathrm{M}=2 \mathrm{OH}+\mathrm{M}$ & $1.20 \times 10^{17}$ & 0.0 & 45.5 & 9 \\
\hline r101. & $\mathrm{H}_{2}^{2} \mathrm{O}_{2}+\mathrm{O} \Rightarrow \mathrm{HO}_{2}+\mathrm{OH}$ & $6.62 \times 10^{11}$ & 0.0 & 3.97 & 25 \\
\hline r102. & $\mathrm{H}_{2}^{2} \mathrm{O}_{2}^{2}+\mathrm{OH}=>\mathrm{H}_{2}^{2} \mathrm{O}+\mathrm{HO}_{2}$ & $7.83 \times 10^{13}$ & 0.0 & 1.327 & 11 \\
\hline r103. & $\mathrm{CO}+\mathrm{O}_{2}=\mathrm{CO}_{2}^{2}+\mathrm{O}^{2}$ & $2.53 \times 10^{12}$ & 0.0 & 47.69 & 25 \\
\hline r104. & $\mathrm{CO}+\mathrm{O}+\mathrm{M} \Rightarrow \mathrm{CO}_{2}+\mathrm{M}$ & $3.24 \times 10^{13}$ & 0.0 & -4.2 & 9 \\
\hline r105. & $\mathrm{CO}+\mathrm{OH}=>\mathrm{CO}_{2}+{ }^{2} \mathrm{H}$ & $4.40 \times 10^{6}$ & 1.5 & -0.741 & 10 \\
\hline r106. & $\mathrm{CO}+\mathrm{HO}_{2}=>\mathrm{CO}_{2}^{2}+\mathrm{OH}$ & $5.75 \times 10^{13}$ & 0.0 & 22.93 & 9 \\
\hline
\end{tabular}

${ }^{a}$ The rate constants for these reactions were estimated using the same rate constant parameters of similar reactions, where the species are formed in the ground electronic state. The references indicate the rate coefficients for the formation reactions of species in the ground state; ${ }^{\mathrm{b}}$ The rate coefficients were obtained from the literature for the quenching of the excited species by $\mathrm{O}_{2}\left(\mathrm{M}=\mathrm{O}_{2}\right)$. However, in the simulations k'=k $[\mathrm{M}]$ where $[\mathrm{M}]=\left[\mathrm{C}_{2} \mathrm{H}_{2}\right]_{0}+\left[\mathrm{O}_{2}\right]_{0}$ is the initial reagent concentrations for each combustion process studied; ${ }^{\mathrm{c}}$ The rate coefficients were the inverse of excited species' lifetime.

by many researchers. ${ }^{9,33,37-40}$ For $\mathrm{OH}^{*}$ chemiluminescence, only one formation reaction $\left(\mathrm{CH}+\mathrm{O}_{2}=>\mathrm{OH}^{*}+\mathrm{CO}\right)$ has been considered and tested by simulations. ${ }^{28,30,37,39-41} \mathrm{In}$ this way, some of the reactions used in our model do not have established kinetic parameters and it was necessary to estimate them.

The Arrhenius parameters for these formation reactions of excited species were estimated from similar reactions, 
which lead to the same species in their ground states, as well as those used for our earlier simulation of ethanol combustion. ${ }^{42}$ This approach was based on activatedcomplex theory ${ }^{16,43}$ and in the fact that reagent species for the formation reactions of the excited species are diatomic and/or atomic.

In the simulated combustion processes, soot particle formation is negligible as our previous study of soot temporal evolution by laser extinction measurements reported. ${ }^{44}$ Hence, elementary reactions for the production of polycyclic aromatic hydrocarbon (PAH) and soot were not included in the initial reaction mechanism.

The proposed reaction mechanism displayed in Table 1 is very different from the initial one described above. To obtain it, the initial model was optimized through the reduction procedure based on ROPA results and later by applying kinetic parameters from other studies, those that better fitted to the experimental chemiluminescence curves of the excited radicals.

The temperature of the combustion processes, in this study, was a parameter adjusted by running the kinetic modeling at different temperatures until to reproduce the experimental chemiluminescence temporal scales. Simulations with $50 \mathrm{~K}$ higher or lower than $1350 \mathrm{~K}$ resulted in chemiluminescence temporal scales very different from those experimentally observed.

The proposed reaction mechanism (Table 1) was fitted to $1350 \mathrm{~K}$ to reproduce the observed experimental chemiluminescence time of about $2.5 \mathrm{~ms}$ in the stoichiometric $\mathrm{C}_{2} \mathrm{H}_{2} / \mathrm{O}_{2}$ combustion $(\Phi=1.00)$ at 140 torr initial pressure. The same reaction mechanism was applied to fuel-rich $\mathrm{C}_{2} \mathrm{H}_{2} / \mathrm{O}_{2}(\Phi=1.62)$ combustion at the same initial pressure (140 torr) and the temperature parameter was adjusted to $1375 \mathrm{~K}$ to reproduce the observed experimental chemiluminescence time of about $3.5 \mathrm{~ms}$.

It is well known that the principal path of acetylene oxidation is the reaction of acetylene with atomic oxygen, producing $\mathrm{CHCO}$ and $\mathrm{CH}_{2}$ radicals as primary products: $1,11,45$

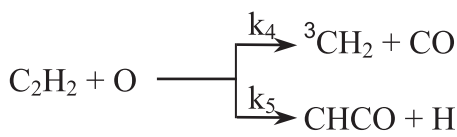

However, there are still polemics about the branching ratio, $\mathrm{k}_{5} / \mathrm{k}_{\mathrm{C} 2 \mathrm{H} 2+\mathrm{O}}$ and the reported determinations show a wide variation. In this work, the branching ratio $\mathrm{k}_{5} / \mathrm{k}_{\mathrm{C} 2 \mathrm{H} 2+\mathrm{O}}$ $=50 \%$, used by Miller and Melius, ${ }^{8}$ was adopted. This value is within the range of the reported determinations and it is that which best fit our experimental chemiluminescence profiles. Frank et al. ${ }^{46}$ cited by Peeters et $a l .,{ }^{26}$ reported a branching ratio of $(64 \pm 15) \%$ in favor of
$\mathrm{CHCO}$ at $1500 \mathrm{~K}$ to $2500 \mathrm{~K}$ and Baulch et al. ${ }^{25}$ deduced $\mathrm{k}_{5} / \mathrm{k}_{\mathrm{C} 2 \mathrm{H} 2+\mathrm{O}}=(70 \pm 20) \%$ for the temperature range of 295 $2500 \mathrm{~K}$. There are also some studies ${ }^{1,11,45}$ suggesting a CHCO-yield of $80 \%$ from the $\mathrm{C}_{2} \mathrm{H}_{2}+\mathrm{O}$ reaction, and possibly as high as $95 \%$ over a wide range of temperatures.

One of products of the $\mathrm{C}_{2} \mathrm{H}_{2}+\mathrm{O}$ reaction is the radical $\mathrm{CH}_{2}$, which is of great importance in acetylene chemistry. This radical can form in both the triplet $\mathrm{CH}_{2}\left({ }^{3} \mathrm{~B}_{1}\right)$ and the singlet $\mathrm{CH}_{2}\left({ }^{1} \mathrm{~A}_{1}\right)$ electronic states. $\mathrm{CH}_{2}\left({ }^{3} \mathrm{~B}_{1}\right)$ is preferentially produced via $\mathrm{C}_{2} \mathrm{H}_{2}+\mathrm{O}(\mathrm{r} 5)$ and the $\mathrm{CHCO}$ $+\mathrm{H}$ reaction $(\mathrm{r} 31)$ is the principal channel of $\mathrm{CH}_{2}\left({ }^{1} \mathrm{~A}_{1}\right)$ formation. ${ }^{1,11}$ Although the reactions for production of both singlet and triplet $\mathrm{CH}_{2}$ radicals are commonly included in the reaction mechanisms, only $\mathrm{CH}_{2}\left({ }^{3} \mathrm{~B}_{1}\right)$ was considered here, since there is a fast conversion of singlet to triplet $\mathrm{CH}_{2}$ radical $\left(\mathrm{CH}_{2}\left({ }^{1} \mathrm{~A}_{1}\right)+\mathrm{M}=\mathrm{CH}_{2}\left({ }^{3} \mathrm{~B}_{1}\right)+\mathrm{M}\right)$ and, thus, it is predominantly formed, as reported in the literature. ${ }^{1,46}$

$\mathrm{CH}_{2}$ radicals are mainly reduced by reaction with $\mathrm{C}_{2} \mathrm{H}_{2}$ to produce $\mathrm{C}_{3} \mathrm{H}_{3}+\mathrm{H}$ in the proposed reaction mechanism. Although this reaction is usually reported for the singlet $\mathrm{CH}_{2}$ radical in kinetic modeling, ${ }^{11,25}$ there are some studies that consider the same reaction for the triplet $\mathrm{CH}_{2}$ radical. ${ }^{47-49}$ The earlier studies applied a rate coefficient for $\mathrm{CH}_{2}\left({ }^{1} \mathrm{~A}_{1}\right)$ and $\mathrm{C}_{2} \mathrm{H}_{2}$ reactions around $2 \times 10^{14} \mathrm{~mol} \mathrm{~cm}$ $\mathrm{s}^{-1} 25$ and some recent studies have used a rate coefficient around $1 \times 10^{12} \mathrm{~mol} \mathrm{~cm} \mathrm{~s}^{-1}$ for the reaction with triplet $\mathrm{CH}_{2}\left({ }^{3} \mathrm{~B}_{1}\right)$ in the temperature range of $1350-1375 \mathrm{~K} .{ }^{47-49}$

In this work, only the reaction $\mathrm{CH}_{2}\left({ }^{3} \mathrm{~B}_{1}\right)+\mathrm{C}_{2} \mathrm{H}_{2}=$ $\mathrm{C}_{3} \mathrm{H}_{3}+\mathrm{H}$ with $\mathrm{k}=1.74 \times 10^{13} \mathrm{~mol} \mathrm{~cm}^{3} \mathrm{~s}^{-1}$ was considered. This rate coefficient is very similar to those used recently by Frenklach and co-workers. ${ }^{48,49}$ for production of propargyl radical via $\mathrm{CH}_{2}\left({ }^{1} \mathrm{~A}_{1}\right)$ to simulate polyaromatic and soot formation.

\section{Results and Discussion}

\section{Initial considerations}

Figures $1 \mathrm{a}$ and $1 \mathrm{~b}$ show the temporal behavior of the total chemiluminescence (light signal detected by the photomultiplier, setting the monochromator to have total reflection) from the $\mathrm{C}_{2} \mathrm{H}_{2} / \mathrm{O}_{2}$ combustions with equivalence ratios $(\Phi)$ equal to 1.0 and 1.62 , respectively. The experimental data show a short time interval to reach maximum chemiluminescence intensity (around $0.55 \mathrm{~ms}$ and $0.65 \mathrm{~ms}$ after starting the increase, respectively, in Figure 1a and in Figure 1b), followed by an intensity decay to zero during a longer time interval (around $2.0 \mathrm{~ms}$ in Figure 1a and ca. $3.0 \mathrm{~ms}$ in Figure 1b).

Based on this temporal behavior, an approximation to the combustion process may be proposed which occurs as 

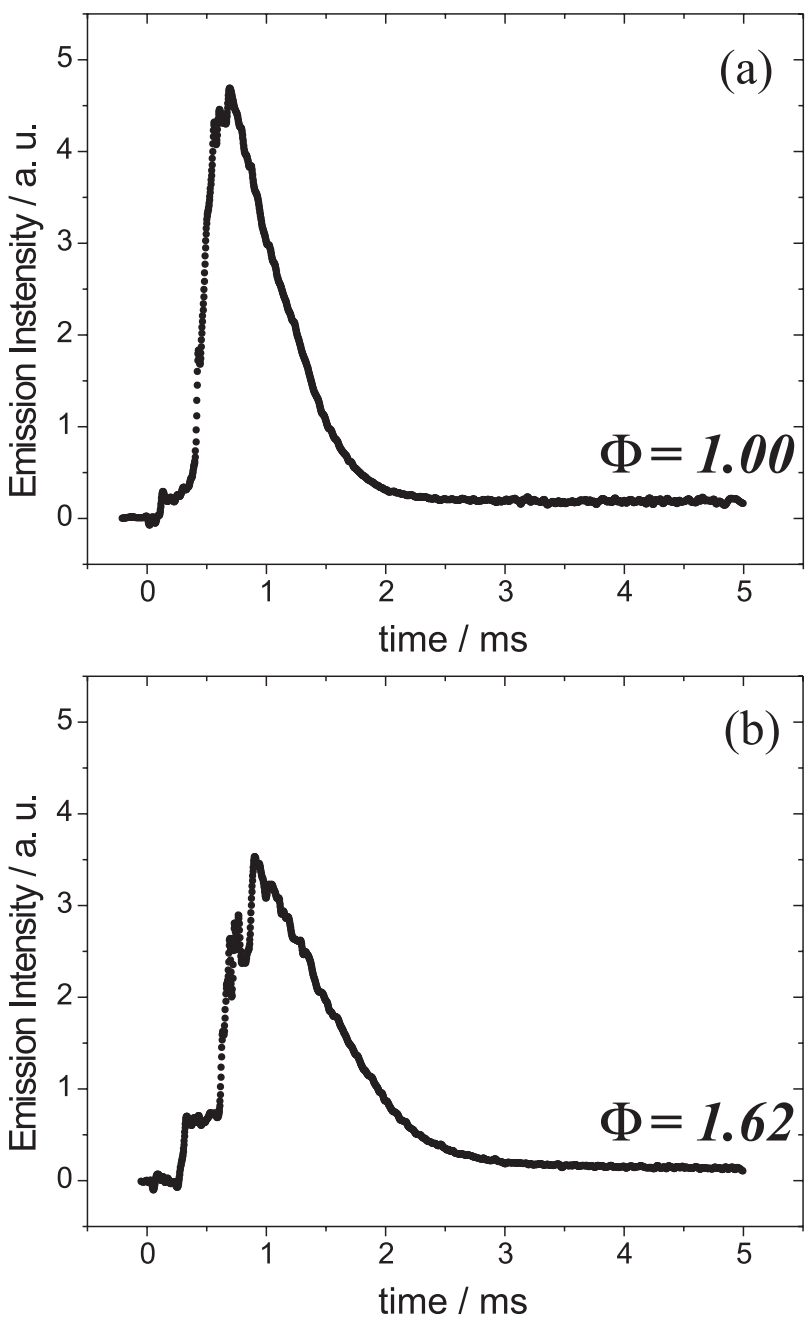

Figure 1. Total chemiluminescence as a function of time for $\mathrm{C}_{2} \mathrm{H}_{2} / \mathrm{O}_{2}$ combustion in a closed chamber (a) $\Phi=1.00$ and (b) $\Phi=1.62$.

two different events. Flame propagation throughout the chamber is the dominant process in the first part of the chemiluminescence process. This part of the combustion process is strongly affected by dynamic factors that are related to the flame propagation phenomenon. After the chemiluminescence reaches its maximum emission intensity, the reagent consumption is the predominant process in the reaction throughout the chamber.

Theoretical and experimental studies are reported in the literature for $\mathrm{C}_{2} \mathrm{H}_{2} / \mathrm{O}_{2}$ combustion under different conditions: shock tubes, open burners, etc. ${ }^{5,6,50,51}$ The results indicate that the combustion shows an initial step, where the intermediate species are formed and the initial reagents are partially consumed. After the initial step, reagent consumption increases and the reaction goes to completion with the formation of stable species.

Since the chemiluminescence temporal behavior is faster in the first process than in the second, the observed chemiluminescence in the second process, where turbulence makes the reaction fairly homogeneous, is considered to be emitted from the entire reacting chamber volume. In the second, slow process, the turbulence results in stirring within the reaction zone, which increases heat transfer and radical diffusion. As some studies ${ }^{50,51}$ have reported that the reagents are only partially consumed in the initial step and the KINAL is a software package for the analysis of homogeneous gas-phase chemical kinetics (it does not include fluid dynamic factors related to the flame propagation, as most of the software package is for combustion kinetic simulations), a better approach is to use the slower second process to describe the combustion reaction as a guideline to validate the model in simulation studies of acetylene combustion in a closed chamber.

This work proposes a mechanism for acetylene combustion including formation reactions for electronically excited species. The simulated temporal behavior of the chemiluminescence originating from the radiative decay of the excited species is compared with the second step of the experimental chemiluminescence, which is used as a criterion for mechanism optimization.

To obtain the simulated chemiluminescence displayed in Figures 2 and 3, the photons emitted, $\mathrm{h} v_{\mathrm{OH}^{*}}, \mathrm{~h} v_{\mathrm{CHO}^{*}}, \mathrm{~h} v_{\mathrm{CH}^{*}}$ and $\mathrm{h} v_{\mathrm{C}^{*}}$, from each corresponding excited radical ( $\mathrm{r} 64$, $\mathrm{r} 67, \mathrm{r} 72, \mathrm{r} 78$ ) were inserted as "species" in the reaction mechanism. The computer simulation results in growth curves of "photon concentration" as a function of time and the differentials of these curves produce the photon production rates as a function of time, which can be associated with the experimental data. The temporal behavior of experimental chemiluminescence can represent the production rate of these excited radicals (number of photons / s) as a function of time, because self-absorption of $\mathrm{OH}, \mathrm{CHO}, \mathrm{CH}$ and $\mathrm{C}_{2}$ is negligible ${ }^{36,52}$ and the total emission time (milliseconds) recorded was a thousand times larger than the lifetimes (microseconds) of excited radicals. ${ }^{14}$

To compare the experimental chemiluminescent profiles with the simulated chemiluminescent profiles, the first part of all curves (which represents the fast flame propagation through the whole chamber) was removed and the curves were normalized to make the first point coincide with zero on the abscissa and with unity on the ordinate. This procedure does not produce any deformation in the curves and allows comparison between the different groups of results. Thus, the simulated and experimental production rates of the excited radicals can be properly compared, since the comparison between the emission intensities (number of photons / s) and the differentials of the "photon concentrations" (generated in the simulation procedure), are not directly possible. 

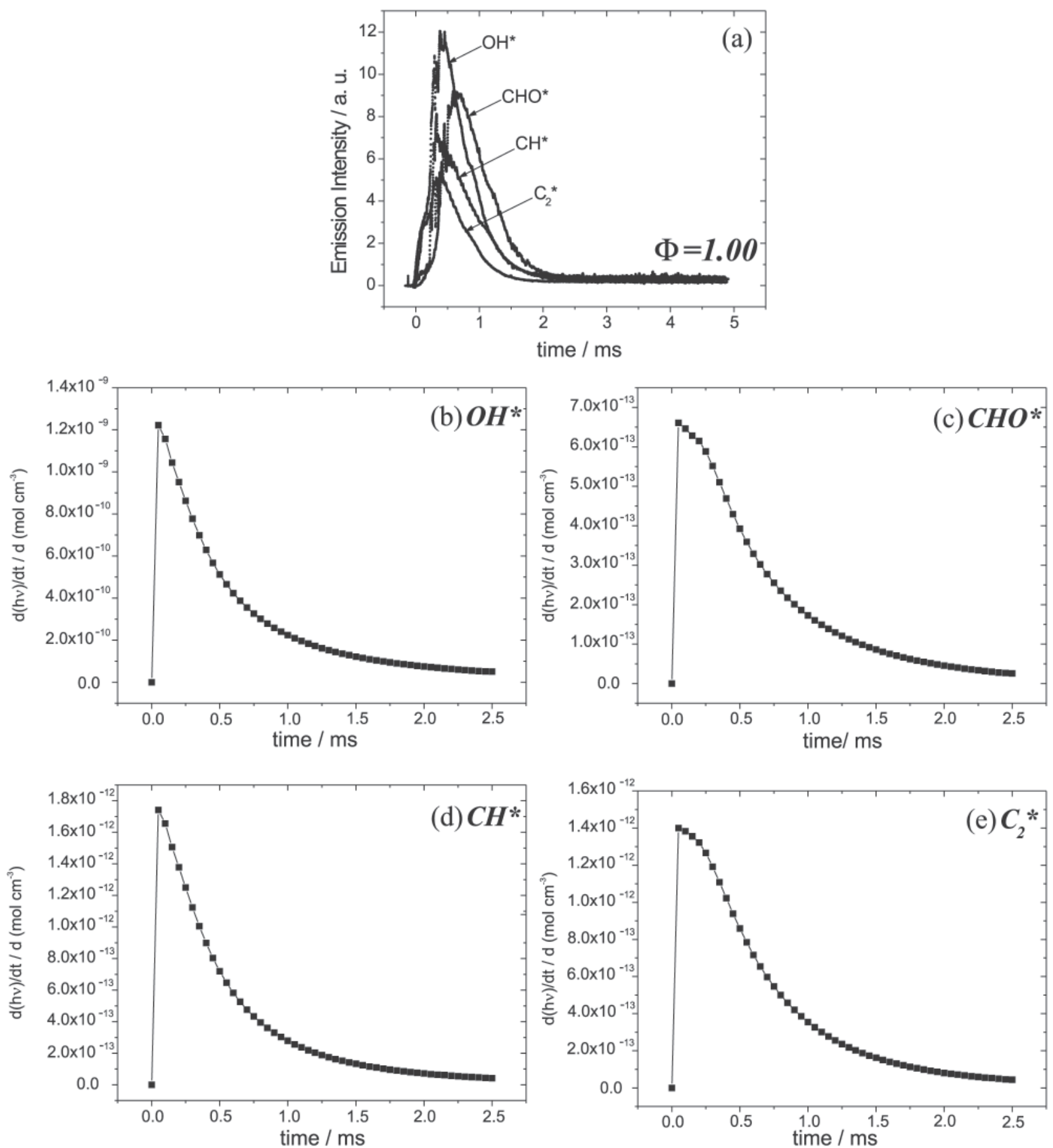

Figure 2. Stoichiometric $\mathrm{C}_{2} \mathrm{H}_{2} / \mathrm{O}_{2}$ combustion. (a) Experimental chemiluminescence profiles of excited radicals obtained from reference 14 and (b, c, d, e, f) simulated chemiluminescence profiles of excited species as indicated.

Similar approaches were done to simulate the formation of the chemiluminescent species in ethanol combustion produced in the same combustion system. ${ }^{42}$

\section{Mechanism for $\mathrm{OH}^{*}\left(A^{2} \Sigma^{+}\right)$radical formation}

The temporal decay of the experimental and simulated chemiluminescence of $\mathrm{OH}^{*}$, presented in Figures 4 (a) and 5 (a) for both stoichiometric and fuel-rich $\mathrm{C}_{2} \mathrm{H}_{2} / \mathrm{O}_{2}$ combustion, showed good agreement.

The formation reactions used to reproduce experimental data were:

$\mathrm{CH}+\mathrm{O}_{2}=\mathrm{OH}^{*}+\mathrm{CO}$

$\mathrm{H}+\mathrm{O}_{2}=\mathrm{OH}^{*}+\mathrm{O}$

$\mathrm{H}+\mathrm{O}=\mathrm{OH}^{*}$ 

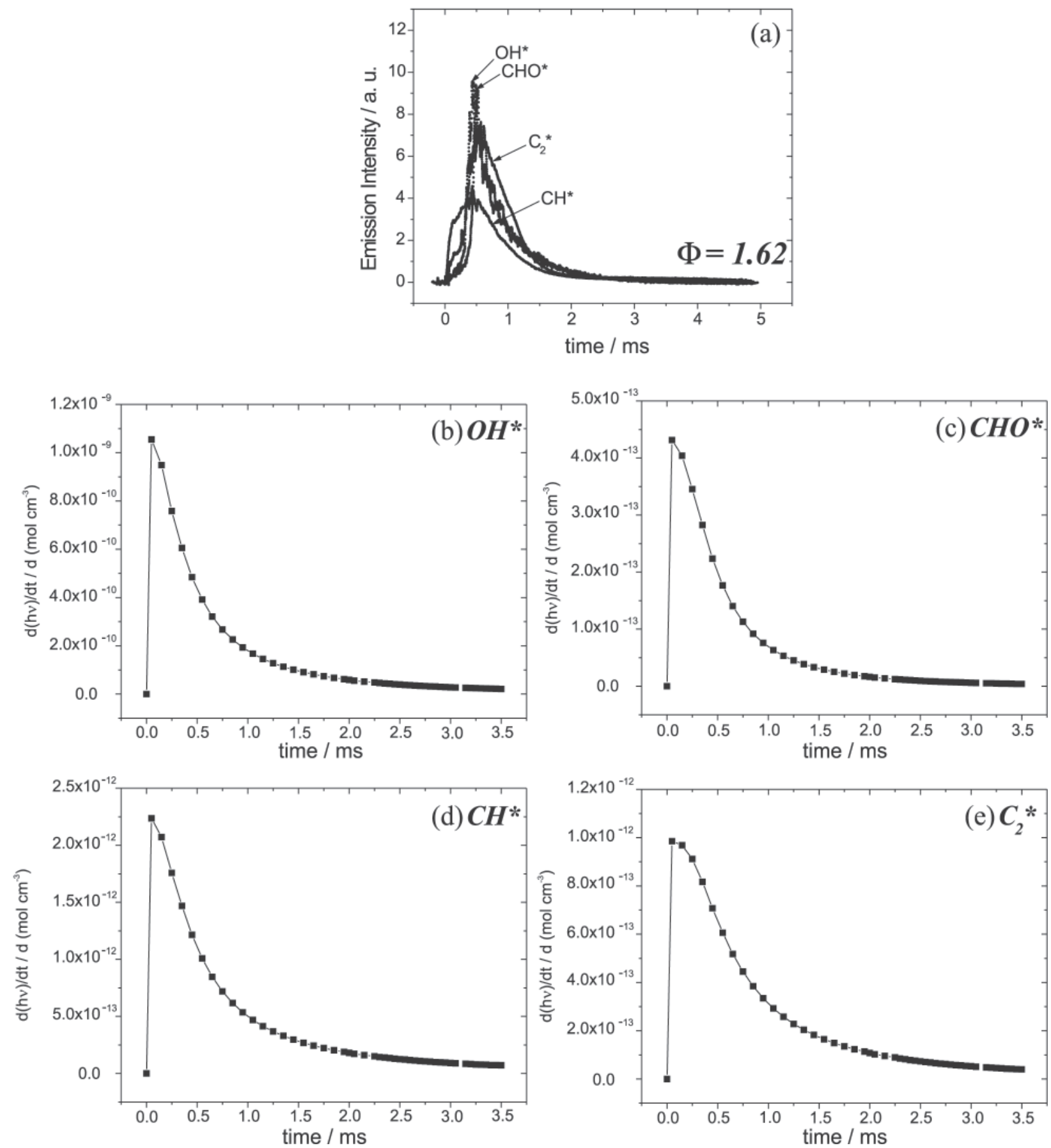

Figure 3. Fuel-rich $\mathrm{C}_{2} \mathrm{H}_{2} / \mathrm{O}_{2}$ combustion. (a) Experimental chemiluminescence profiles of excited radicals obtained from reference 14 and (b, c, d, e, f) simulated chemiluminescence profiles of excited species as indicated.

Gaydon $^{36}$ originally suggested reaction (r60) and Gaydon and Wolfhard ${ }^{53}$ proposed reaction (r62) for hydrogen flames for $\mathrm{OH}^{*}$ chemiluminescence. Both reactions (r60) and (r62) are exothermic enough to produce $\mathrm{OH}^{*}$ in the excited electronic state, around $159 \mathrm{kcal}$ $\mathrm{mol}^{-1}$ and $101 \mathrm{kcal} \mathrm{mol}^{-1}$, respectively.

Reaction (r61), in spite of being slightly endothermic $\left(16 \mathrm{kcal} \mathrm{mol}^{-1}\right),{ }^{54}$ was proposed by Shuler ${ }^{55}$ for hydrogen flames. Shuler ${ }^{55}$ based on analysis of potential energy surfaces, showed $\mathrm{OH}^{*}$ production through a $\left[\mathrm{HO}_{2}\right]$ complex intermediate. Two reaction paths are possible, one from excited $\mathrm{O}_{2}{ }^{*}$ and another from $\mathrm{O}_{2}$ in the ground state.

$\mathrm{H}+\mathrm{O}_{2}^{*}\left({ }^{3} \Sigma_{\mathrm{u}-}\right) \rightarrow\left[\mathrm{HO}_{2}\left({ }^{2} \mathrm{~A}^{\prime \prime}\right)\right] \rightarrow \mathrm{O}+\mathrm{OH}^{*}\left({ }^{2} \Sigma^{+}\right)$

$\mathrm{H}+\mathrm{O}_{2}\left({ }^{3} \Sigma_{\mathrm{g}}\right) \rightarrow\left[\mathrm{HO}_{2}\left({ }^{2} \mathrm{~A}^{\prime \prime}\right)\right] \rightarrow \mathrm{O}+\mathrm{OH}^{*}\left({ }^{2} \Sigma^{+}\right)$ 
However, none of these authors supplied the reaction kinetic parameters. For both reactions (r61) and (r62), kinetic parameters were obtained from similar reactions that produce $\mathrm{OH}$ in the ground electronic state. ${ }^{11,25}$ Since in the first case, the activated complex is the same for both reaction paths to production of ground $\mathrm{OH}\left(\mathrm{X}^{2} \Pi\right)$ and excited $\mathrm{OH}^{*}\left({ }^{2} \Sigma^{+}\right)$, this approach is valid. In the second, the recombination reaction (r62) would need a third body (M) (to transfer the excess energy) to produce $\mathrm{OH}$ in the ground state, so the same rate constant without $\mathrm{M}$ in the reaction is suitable.

The reaction ( $\mathrm{r} 60$ ) has usually been attributed to $\mathrm{OH}^{*}$ chemiluminescence. For this reason the rate constant used by Berman et al. ${ }^{28}$ that gives the higher value, was adopted in this work, to test the other possible reactions for $\mathrm{OH}^{*}$ chemiluminescence. In this way, the rate constant for reaction (r60) is about hundred times higher than that for reaction (r61) at the temperatures used. The simulated chemiluminescence profiles without (r61) in the reaction mechanism did not fit the experimental chemiluminescence profiles very well.

In this study, the radiative rate for $\mathrm{OH}^{*}\left(\mathrm{~A}^{2} \Sigma^{+}\right)$radical was $1.70 \times 10^{6} \mathrm{~s}^{-1}$, the same value adopted by Berman et $a l .{ }^{28}$ and the collisional quenching rate was taken from Tamura et $_{\text {al. }}{ }^{29}$

ROPA analysis indicated that, in the purposed reaction mechanism, reaction ( $\mathrm{r} 61$ ) is the principal route for $\mathrm{OH}^{*}$ formation and it contributes to about $90 \%$ of the total amount of $\mathrm{OH}^{*}$. The other reactions ( $\mathrm{r} 60$ and r62) together are responsible for around $10 \%$ of $\mathrm{OH}^{*}$ production.

\section{Mechanism for $\mathrm{CHO}^{*}\left(A^{2} \Pi\right)$ radical formation}

There is also a good fit between the simulated and experimental chemiluminescence data for the $\mathrm{CHO}^{*}$ radical for both stoichiometric and fuel-rich $\mathrm{C}_{2} \mathrm{H}_{2} / \mathrm{O}_{2}$ combustion, as shown in Figures 4 (b) and 5 (b).

To reproduce the experimental chemiluminescence of CHO*, only a single formation reaction of this radical was found in the literature, suggested by Gaydon, ${ }^{36}$ and it was inserted in the reaction mechanism.

$\mathrm{CH}+\mathrm{O}=\mathrm{CHO}^{*}$

According to Sappey and Crosley, ${ }^{32}$ the $\mathrm{CHO}^{*}\left(\mathrm{~A}^{2} \Pi\right)$ lifetime is $30 \mathrm{ps}$ and presents a low quantum fluorescence yield. In spite of this, the radical $\mathrm{CHO}^{*}$ shows several emission bands in the UV-Visible region from $250 \mathrm{~nm}$ to $400 \mathrm{~nm}$ that are features of hydrocarbon flames. ${ }^{32,36}$

Kinetic parameters for reaction ( $(65)$ were not found in the literature, the rate coefficient established ${ }^{25}$ for a similar reaction, $\mathrm{CH}+\mathrm{O}=\mathrm{H}+\mathrm{CO}$ (exothermic, 57-65 kcal $\left.\mathrm{mol}^{-1}\right),{ }^{56}$ was applied to this reaction.

\section{Mechanism for $\mathrm{CH}^{*}\left(A^{2} \Delta\right)$ radical formation}

Experimental and simulated chemiluminescences of the $\mathrm{CH}^{*}$ radical are shown in Figures 4 (c) and 5 (c). Again the model reproduces the experimental data with good agreement for both stoichiometric and fuel-rich $\mathrm{C}_{2} \mathrm{H}_{2} /$ $\mathrm{O}_{2}$ combustion.

Although the mechanism of $\mathrm{CH}^{*}$ formation has not yet been definitely established, it is one of the most studied excited radicals. Most of these studies, the reaction between $\mathrm{C}_{2} \mathrm{H}$ and $\mathrm{O}$ was found to be the main source of $\mathrm{CH}^{*}$ radical. ${ }^{33,37}$

To reproduce the experimental chemiluminescent profile of $\mathrm{CH}^{*}$ radical, the reactions proposed initially by Hand and Kistiakowsky ${ }^{56}$ (r68 and r69) and reaction (r70), suggested by Gaydon, ${ }^{36}$ were tested.

$\begin{array}{ll}\mathrm{C}_{2} \mathrm{H}+\mathrm{O}_{2}=\mathrm{CH}^{*}+\mathrm{CO}_{2} & \left(-75 \mathrm{kcal} \mathrm{mol}^{-1}\right) \\ \mathrm{C}_{2} \mathrm{H}+\mathrm{O}=\mathrm{CH}^{*}+\mathrm{CO} & \left(-117 \mathrm{kcal} \mathrm{mol}^{-1}\right)^{37} \\ \mathrm{C}_{2}+\mathrm{OH}=\mathrm{CH}^{*}+\mathrm{CO} & \left(-91 \mathrm{kcal} \mathrm{mol}^{-1}\right)\end{array}$

$\mathrm{C}_{2} \mathrm{H}$ radicals could be found in vibrationally excited states $^{37}$ increasing $c a .-12 \mathrm{kcal}$ for reactions (r68) and (r69).

Kinetic parameters for reactions (r68) and (r70) were taken from Eraslan and Brown ${ }^{9}$ and the kinetic parameters for the latter reaction are the same as those adopted by Grebe and Homann. ${ }^{37}$ For reaction (r69), the kinetic parameters were from Devriendt and Peeters. ${ }^{33}$ The $\mathrm{CH}^{*}$ $\left(\mathrm{A}^{2} \Delta\right)$ radical lifetime is $(0.56 \pm 0.06) \mu \mathrm{s}^{34}$ and its nonradiative rate was taken from Tamura et al. ${ }^{29}$

ROPA analysis indicates that only reaction (r68) is important in this reaction mechanism for $\mathrm{CH}^{*}$ production, in order to fit the simulated chemiluminescence of this radical to its experimental chemiluminescence. The other two reactions (r69) and (r70) were discarded by ROPA analysis. Grebe and Homann ${ }^{37}$ also discard reaction (r70), due to the low concentration of $\mathrm{C}_{2}$ radical in the ground state and our results support their conclusion.

\section{Mechanism for $C_{2}\left(A^{3} \Pi_{g}\right)$ radical formation}

The temporal decay of experimental and simulated chemiluminescence of $\mathrm{C}_{2}{ }^{*}$, presented in Figures 4 (d) and 5 (d), showed good agreement for both stoichiometric and fuel-rich $\mathrm{C}_{2} \mathrm{H}_{2} / \mathrm{O}_{2}$ combustion.

Four formation reactions for $\mathrm{C}_{2} *$ radical were inserted in the reaction mechanism to try to reproduce its experimental chemiluminescence. Reactions (r73) and (r76) were originally proposed by Gaydon. ${ }^{36}$ Miller and Palmer $^{57}$ proposed reaction (r74) and Fergunson ${ }^{58}$ suggested reaction (r75). 

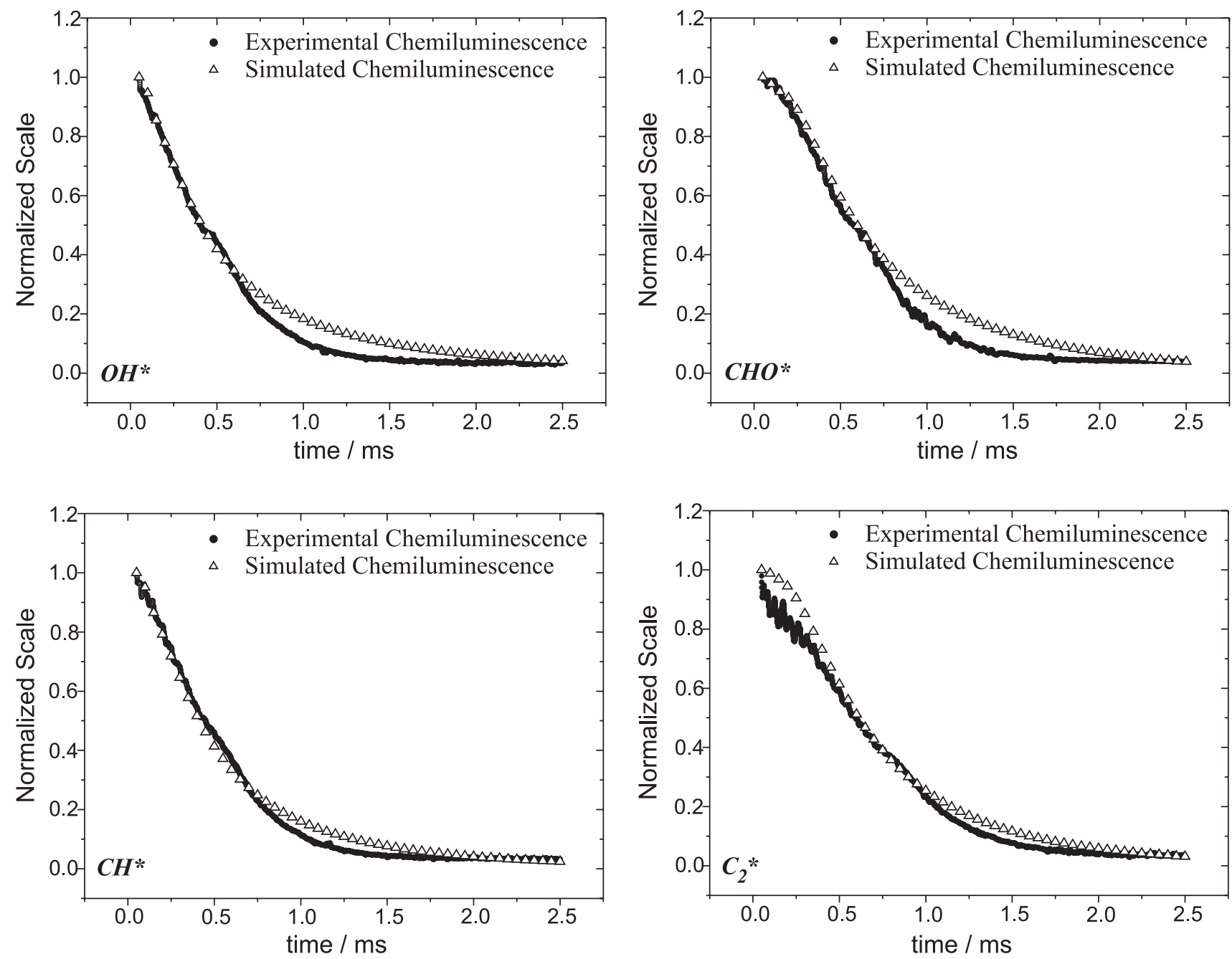

Figure 4. Stoichiometric $\mathrm{C}_{2} \mathrm{H}_{2} / \mathrm{O}_{2}$ combustion. Comparison between experimental chemiluminescence profiles (circles) and simulated chemiluminescence profiles (triangles) of excited species as indicated.

$$
\begin{array}{ll}
\mathrm{CH}_{2}+\mathrm{C}=\mathrm{C}_{2} *+\mathrm{H}_{2} & \left(-63 \mathrm{kcal} \mathrm{mol}^{-1}\right)^{37} \\
\mathrm{CH}+\mathrm{C}=\mathrm{C}_{2}{ }^{*}+\mathrm{H} & \left(-59 \mathrm{kcal} \mathrm{mol}^{-1}\right)^{37} \\
2 \mathrm{CH}=\mathrm{C}_{2} *+\mathrm{H} & \left(-82 \mathrm{kcal} \mathrm{mol}^{-1}\right)^{37} \\
\mathrm{C}_{2} \mathrm{H}+\mathrm{H}=\mathrm{C}_{2} *+\mathrm{H}_{2} & \text { (thermoneutral) }
\end{array}
$$

According to Fergunson, ${ }^{58}$ reaction (r76) does not contribute very much to $\mathrm{C}_{2} *$ formation, because experiments with isotope substitution show that a $\mathrm{C}_{2} \mathrm{H}_{n}$ fragment from a $\mathrm{C}_{2} \mathrm{H}_{2}$ fuel molecule could not be the main precursor of this excited radical. There is strong evidence in the literature ${ }^{37,59,60}$ that the reaction between two $\mathrm{CH}$ radicals (r75) does not contribute significantly to $\mathrm{C}_{2}{ }^{*}$ production. Grebe and Homann ${ }^{37}$ also discard reaction (r74) and proposed reaction (r73) for $\mathrm{C}_{2} *$ formation.

In this work, the simulation results show that the reaction between $\mathrm{CH}_{2}$ and $\mathrm{C}(\mathrm{r} 73)$ is the main source of the $\mathrm{C}_{2} *$ excited radical, contributing to about $98 \%$ of the total amount. Reactions (r74) and (r76) have small contributions, around of $2 \%$, and reaction (r75) does not contribute to $\mathrm{C}_{2}^{*}$ production.

Kinetic parameters used to test reactions (r73), (r74) and (r75) were applied by Williams and Pasternack ${ }^{27}$ for similar reactions of $\mathrm{C}_{2}$ in the ground electronic state. For reaction $(\mathrm{r} 76)$ the kinetic parameters employed were also taken from similar reactions of the Eraslan and Brown ${ }^{9}$ study. The lifetime of $\mathrm{C}_{2} *\left(\mathrm{~A}^{3} \Pi_{\mathrm{g}}\right)$ radical is $(0.17 \pm 0.02)$ $\mu \mathrm{s}^{36}$ and its collisional deactivation rate was taken from Filseth et $a l .{ }^{35}$

\section{Important reaction paths}

The influence of reactions and intermediate species on the simulated chemiluminescence profiles was tested before the optimization of the proposed reaction mechanism, by changing the rate coefficient values within their error limits. It was verified that these changes in the kinetic parameters 

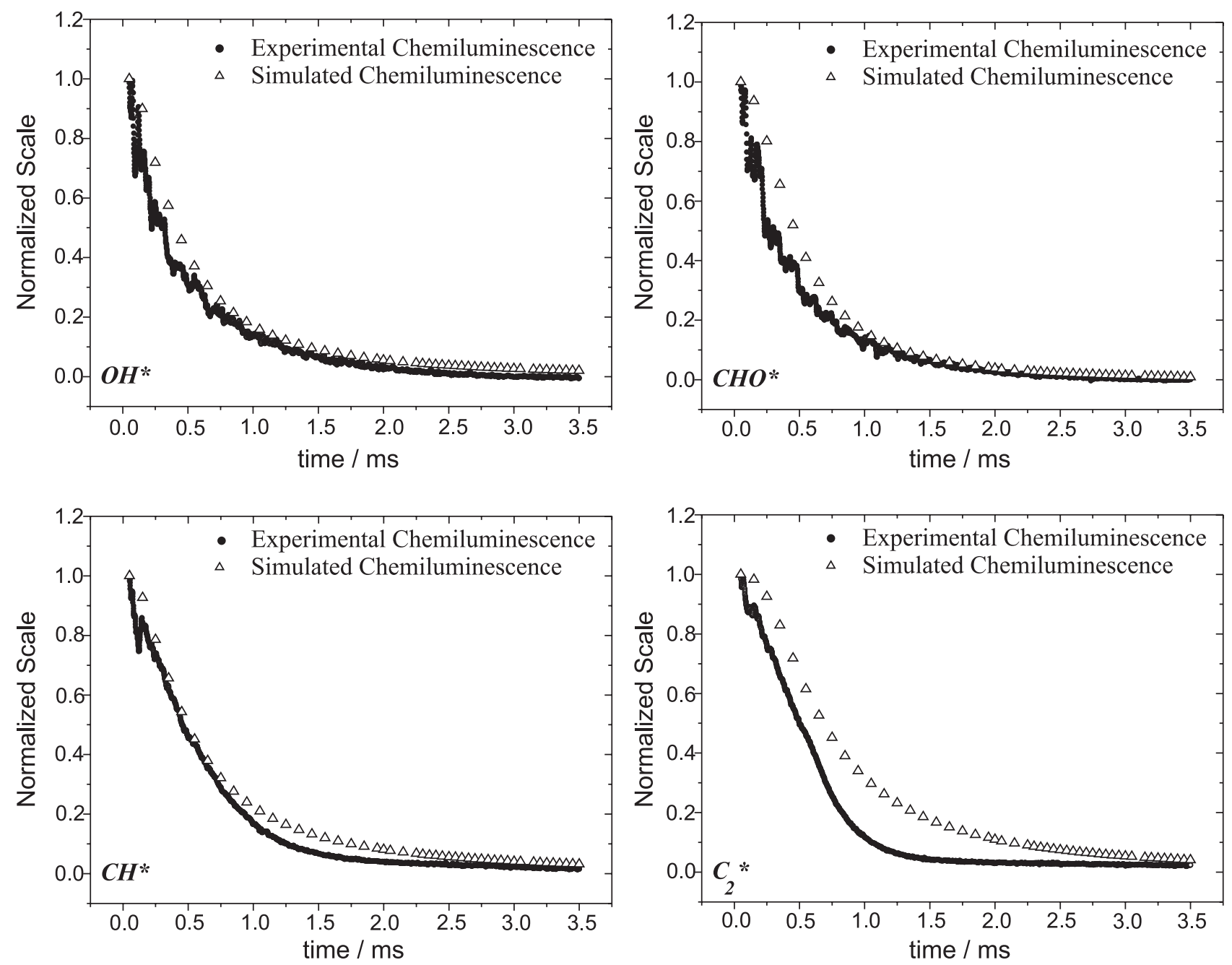

Figure 5. Fuel-rich $\mathrm{C}_{2} \mathrm{H}_{2} / \mathrm{O}_{2}$ combustion. Comparison between experimental chemiluminescence profiles (circles) and simulated chemiluminescence profiles (triangles) of excited species as indicated.

of the formation reactions of excited radicals have almost no influence on the simulated chemiluminescence profiles. However, the simulated chemiluminescence profiles are strongly affected by changes in the rate coefficients of reactions that lead to the main precursors $\left(\mathrm{CH}_{2}\right.$ and $\left.\mathrm{CHCO}\right)$ of most of the excited radicals.

The most important reactions for production and consumption of each species inserted in the reaction mechanism were determined through production rate analysis by ROPA. Figure 6 shows the reaction scheme built from ROPA analysis results at $\mathrm{t}=0.05 \mathrm{~ms}$. ROPA analysis was also carried out at $\mathrm{t}=0.50 \mathrm{~ms}$ to verify the changes in the importance of different reactions with temporal evolution. As there is practically no change in a reaction's importance as a function of reaction time, the scheme in Figure 6 can properly represent the reaction paths of acetylene oxidation over the whole reaction period.
The proposed reaction mechanism shows three main routes to acetylene oxidation (Figure 6). The first leads to the formation of $\mathrm{C} 2$ and $\mathrm{C} 3$ species through production of the propargyl radical $\left(\mathrm{C}_{3} \mathrm{H}_{3}\right)$ and contributes about $20 \%$ to acetylene oxidation. Another route results in oxygenated species such as formaldehyde, water and hydrogen peroxide, via $\mathrm{CH}_{2} \mathrm{CO}$ formation; this route also contributes about $20 \%$ to acetylene oxidation. The third is the main route that contributes approximately $60 \%$ to acetylene consumption and gives the $\mathrm{CH}_{2}$ and $\mathrm{CHCO}$ primary radicals, which are the precursors of most of the excited radicals.

Both primary radicals, $\mathrm{CH}_{2}$ and $\mathrm{CHCO}$, take part in the production of $\mathrm{CH}$ radical in the ground electronic state. $\mathrm{CH}$ radical has a meaningful role in the formation of excited radicals, despite neither always being directly involved in the production of these species. $\mathrm{CH}$ radicals are directly linked to $\mathrm{OH}^{*}$ and $\mathrm{CHO}^{*}$ formation from 


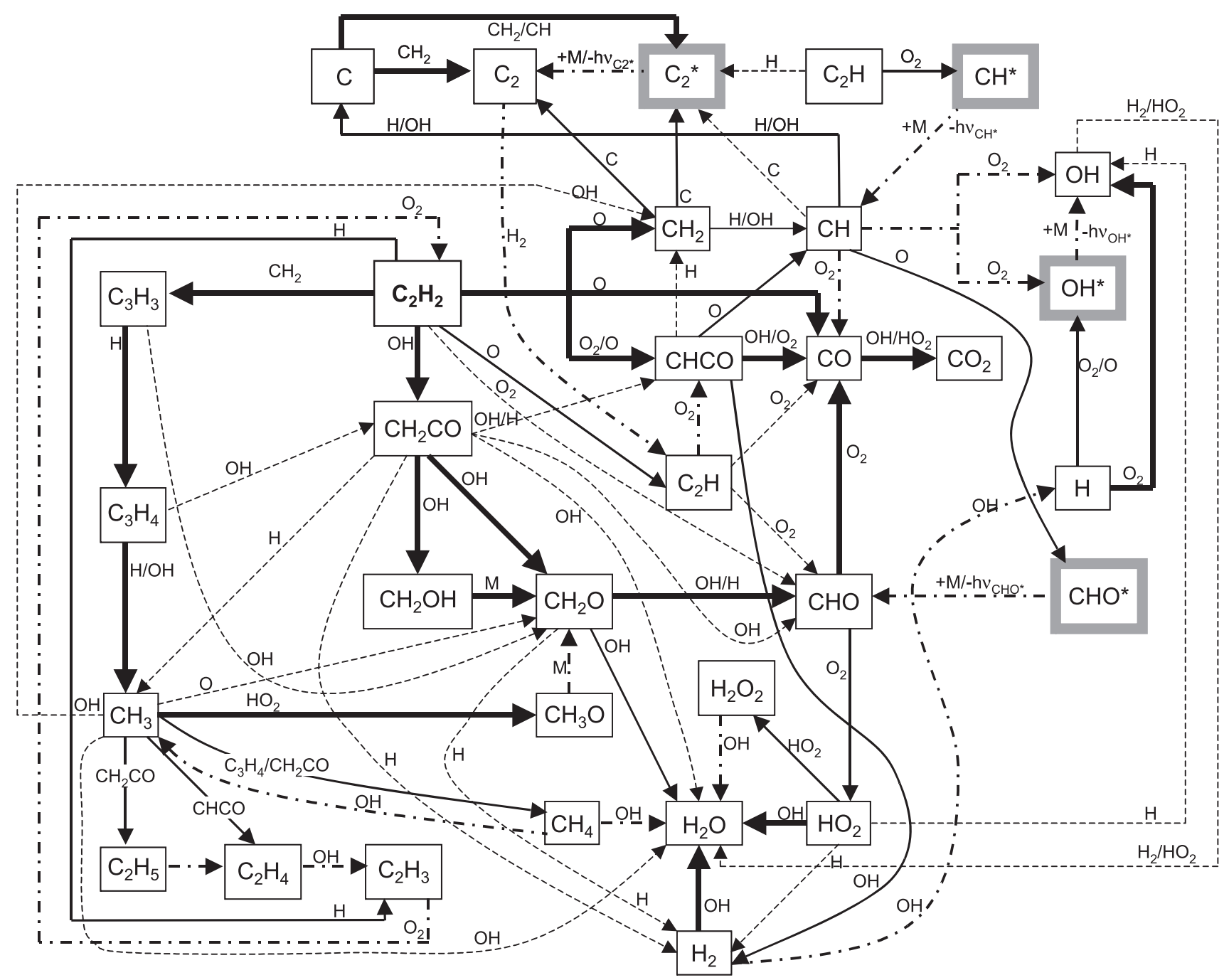

Figure 6. Scheme of the most important reaction paths of acetylene oxidation in the proposed reaction mechanism. Large arrows $(\rightarrow)$ : important reactions for the formation and consumption of species. Solid arrows $(\longrightarrow)$ : important reactions for the formation of species. Dash-dot arrows $(-\cdots)$ : important reactions for the consumption of species. Dash arrows (---): reactions with smaller contributions for the formation and consumption of species.

molecular and atomic oxygen reactions, respectively, although the reaction between $\mathrm{CH}$ and $\mathrm{O}_{2}$ contributes only slightly to $\mathrm{OH}^{*}$ production. On the other hand, the $\mathrm{CH}$ radical is the principal precursor of atomic carbon, which participates in the most important reaction for $\mathrm{C}_{2}{ }^{*}$ production. Only $\mathrm{CH}^{*}$ excited radical is directly produced from the acetylene molecule, since this latter is the main source of $\mathrm{C}_{2} \mathrm{H}$ radicals.

\section{Conclusions}

The experimental chemiluminescence profiles obtained in $\mathrm{C}_{2} \mathrm{H}_{2} / \mathrm{O}_{2}$ combustion were reproduced by kinetic modeling, which includes formation and decay reactions for the excited radicals. The proposed mechanism shows a good agreement between simulated and experimental chemiluminescence data of $\mathrm{OH}^{*}$,
CHO*, $\mathrm{CH}^{*}$ and $\mathrm{C}_{2}{ }^{*}$ excited radicals for both $\mathrm{C}_{2} \mathrm{H}_{2} / \mathrm{O}_{2}$ combustions under stoichiometric $(\Phi=1.00)$ and fuelrich $(\Phi=1.62)$ conditions.

The present paper and our earlier ethanol study ${ }^{42}$ show the possibility of using experimental chemiluminescence data as a guideline to validate kinetic modeling and to understand the chemistry of small hydrocarbon radicals in similar combustion systems (closed chamber with small volume), since flame propagation is very fast and the greatest part of the combustion processes can be represented by a fairly homogeneous reaction and, thus, properly simulated by KINAL and other software packages for combustion kinetic simulations.

Analysis of production rates showed $\mathrm{CH}_{2}$ and $\mathrm{CHCO}$ radicals as the main precursors of most of excited radicals, through $\mathrm{CH}$ radical production in the ground state, which has a central role in the processes of 
formation of the chemiluminescent species. The most important reaction paths identified by production rate analysis for formation of excited species that are responsible for the simulated chemiluminescence profiles are: $\mathrm{H}+\mathrm{O}_{2}=\mathrm{OH}^{*}+\mathrm{O} ; \mathrm{CH}+\mathrm{O}=\mathrm{CHO}^{*} ; \mathrm{C}_{2} \mathrm{H}+\mathrm{O}_{2}=$ $\mathrm{CH}^{*}+\mathrm{O}_{2}$ and $\mathrm{CH}_{2}+\mathrm{C}=\mathrm{C}_{2}{ }^{*}+\mathrm{H}_{2}$.

\section{Acknowledgments}

The authors are grateful to FAPESP (Fundação de Amparo à Pesquisa do Estado de São Paulo) for financial support through projects 96/09627-9 and 97/07938-0.

\section{References}

1. Peeters, J.; Bull. Soc. Chim. Belg. 1997, 106, 337.

2. Levy, J. M; Combust. Flame 1982, 46, 7.

3. Koike, T.; Morinaga, K.; Bull. Chem. Soc. Jpn 1987, 60, 4229.

4. Frenklach, M.; Warnatz, J.; Combust. Sci. Technol. 1987, 51 265.

5. Westmoreland, P. R.; Howard, J. B.; Longwell, J. P.; Proc. Combust. Inst. 1986, 21, 773.

6. Westmoreland, P. R.; Dean, A. M.; Howard, J. B.; Longwell, J. P.; J. Phys. Chem. 1989, 93, 8171.

7. Miller, J. A.; Volponi, J. V.; Durant Jr., J. L.; Goldsmith, J. E. M.; Fisk, G. A.; Kee, R. J.; Proc. Combust. Inst. 1990, 23, 187.

8. Miller, J. A.; Melius, C. F.; Combust. Flame 1992, 91, 21.

9. Eraslan, A. N.; Brown, R. C.; Combust. Flame 1988, 74, 19.

10. Hidaka, Y.; Hattori, K.; Okuno, T.; Inami, K.; Abe, T.; Koike, T.; Combust. Flame 1996, 107, 401.

11. Lindstedt, R. P.; Skevis, G.; Combust. Sci. Technol. 1997, 125, 73.

12. Williams, B.; Fleming, J. W.; Combust. Flame 1995, 100, 571.

13. Hartlieb, A. T.; Atakan, B.; Kohse-HöInghaus, K.; Combust. Flame 2000, 121, 610.

14. Bertran, C. A.; Marques, C. S. T.; Benvenutti, L. H.; Combust. Sci. Technol. 2001, 167, 113.

15. Turányi, T.; J. Math. Chem. 1990, 5, 203.

16. Steinfeld, J. I.; Francisco, J. S.; Hase, W. L.; Chemical Kinetics and Dynamics, Prentice-Hall: New Jersey, 1989.

17. Pilling, M. J. Modern Gas Kinetics, Blackwell: Oxford, 1987

18. Hirst, D.M.; A Computational Approach to Chemistry, Blackwell Scientific Publications: Oxford, 1990.

19. Turányi, T.; Comput. Chem. 1990, 14, 253.

20. Kaps, P.; Rentrop, P.; Numer. Math. 1979, 33, 55.

21. Gelinas, R. J.; Science Applications, Inc., Preprint No. AI/PL/ C279, 1979.

22. Kee, R. J.; Grcar, J. F.; Smooke, M. D.; Miller, J. A.; Report No. SAND85-8240, Sandia National Laboratories, 1985.

23. Gardiner Jr., W. C.; J. Phys. Chem. 1977, 81, 2367.

24. Pimentel, A. S.; Arbilla, G.; J. Braz. Chem. Soc. 1998, 9, 539
25. Baulch, D. L.; Cobos, C. J.; Cox, R. A.; Frank, P.; Hayman, G.; Just, T.; Kerr, J. A.; Murrells, T.; Pilling, M. J.; Troe, J.; Walker R. W.; Warnatz, J.; J. Phys. Chem. Ref. Data 1994, 23, 847.

26. Peeters, J.; Boullart, W.; Devriendt, K.; J. Phys. Chem. 1995 , 99, 3583

27. Williams, B. A.; Pasternack, L.; Combust. Flame 1997, 111, 87.

28. Berman, M. R.; Fleming, J. W.; Harvey, A. B.; Lin, M. C.; Proc. Combust. Inst. 1982, 19, 73.

29. Tamura, M.; Berg, P.A.; Harrington, J. E.; Luque, J.; Jeffries, J. B.; Smith, G. P.; Crosley, D. R.; Combust. Flame 1998, 114, 502.

30. Dandy, D. S.; Vosen, S. R.; Combust. Sci. Technol. 1992, 82, 131.

31. Meier, U. E.; Hunziker, L. E.; Crosley, D. R.; J. Phys. Chem. 1991, 95, 5163.

32. Sappey, A. D.; Crosley, D. R.; J. Chem. Phys. 1990, 93, 7601.

33. Devriendt, K.; Peeters, J.; J. Phys. Chem. 1997, 101, 2546.

34. Gaydon, A.G.; Flames - Their Structure, Radiation and Temperature, $3^{\text {rd }}$ ed, Chapman and Hall: London, 1970.

35. Filseth, S. V.; Hancock, G.; Fournier, J.; Meier, K.; Chem. Phys. Lett. 1979, 61, 288.

36. Gaydon, A. G. The Spectroscopy of Flames, John Wiley, New York, 1974.

37. Grebe, J.; Homann, K. H.; Ber. Der Bunsenges. Phys. Chem. Chemical Physycs 1982, 86, 587.

38. Devriendt, K.; Van Look, H.; Ceursters, B.; Peeters, J.; Chem. Phys. Lett. 1996, 261, 450.

39. Walsh, K.T.; Long, M.B.; Tanoff, M.A.; Smooke, M.D.; Proc. Combust. Inst. 1998, 27, 615

40. Smith, G. P.; Luque, J.; Park, C.; Jeffries, J. B.; Crosley, D. R.; Combust. Flame 2002, 131, 59

41. Marchese, A. J.; Dryer, F. L.; Nayagam, V.; Colantonio, R.O.; Proc. Combust. Inst. 1996, 26, 1219.

42. Benvenutti, L. H.; Marques, C. S. T.; Bertran, C. A.; Combust. Sci. Technol. 2005, 177, 1.

43. Levine, I. Physical Chemistry, McGraw Hill, Inc., 1988.

44. Bertran, C. A.; Marques, C. S. T.; Benvenutti, L. H.; J. Braz. Chem. Soc. 2002, 13, 47.

45. Michael, J. V.; Wagner, A. F.; J. Phys. Chem. 1990, 94, 2453.

46. Frank, F.; Bhaskarn, K. A.; Just, Th.; Proc. Combust. Inst. 1986, 21,885 .

47. Laskin, A.; Wang, H.; Chem. Phys. Lett. 1999, 303, 43. (http:/ /ignis.me.udel.edu/mech)

48. Frenklach, M.; Wang, H.; Combust. Flame 1997, 110, 173.

49. Frenklach, M.; Appel, J.; Bockhorn, H.; Combust Flame 2000, 121,122

50. D’Anna, A.; Violi, A.; D’Alessio, A.; Combust. Flame 2000, 121,418

51. Varatharajan, B.; Williams, F. A.; Combust. Flame 2001, 124, 624. 
52. Vaidya, D. B.; Horvath, J. J.; Green, A. E. S.; Appl. Opt. 1982, 21, 3357.

53. Gaydon, A. G.; Wolfhard, H. G.; Proc. Roy. Soc. London 1951, A208, 63.

54. Mavrodineanu, R.; Boiteux, H. Flame Spectroscopy, John Wiley \& Sons, Inc., New York, 1965.

55. Shuler, K. E.; J. Chem. Phys. 1953, 21, 624.

56. Hand, C. W.; Kistiakowsky, G. B.; J. Chem. Phys. 1962, 37, 1239.

57. Miller, W. J.; Palmer, H. B.; J. Chem. Phys. 1964, 40, 3701.
58. Fergunson, R. E.; J. Chem. Phys. 1955, 23, 2085.

59. Bleekrode, R.; Nieuwpoort, W.C.; J. Chem. Phys. 1965, 43, 3680.

60. Bulewicz, E. M.; Padley, P. J.; Smith, R. E.; Proc. Roy. Soc. London 1970, A315, 129.

Received: July 27, 2005

Published on the web: February 13, 2006

FAPESP helped in meeting the publication costs of this article. 